\title{
Pattern Recognition through Dip for Wind Turbine
}

\author{
S. Bharathi, K. Madhuleka, V. J. Vijayalakshmi, R. Uthirasamy
}

Abstract: This paper depicts the realization of DIP (Digital Image Processing) technique for pattern recognition to identify objects in video stream. The proposed model compares the test object with standard model and identifies the missing objects in the test item. The model uses image classifier algorithm as a tool. The simulations are carried out in MATLab Simulink and various test items are compared under different morphological conditions. The model is fabricated to analyze and indicate the omitted components in wind turbine.

Keywords: Digital Image Processing, Image Acquisition, segmentation, image classifier

\section{INTRODUCTION}

In the modern era, it is difficult to easily detect the missing components within the real time basis. Comparing and detecting the missing components in the set of components used for the manufacture of wind turbine on the real-time basis is difficult nowadays. There is a problem for the manufacturer to detect the missing components while production of wind turbines and its detection can be made only after the set up the whole wind mill .So it become very difficult to disassemble the turbine and it is very costly and loss of man power. But this difficulty can be made easy by using digital image processing. Our project depicts the realization of DIP (Digital Image Processing) technique for pattern recognition to identify objects. It is a new, easy and effective process to found out the missing objects that are classed together. It is helpful in detecting the missing object in a group of objects that are to be placed together. A digital image processing prevents to enhance features of missing objects with the relevant information about the application and fetches the useful information about the application (data) from the image processing in MATLAB. In recent years, digital image processing has become economical in many fields like signature recognition, iris recognition and face recognition, in forensic, in automobile detection and in military application. Each of these applications has its basic requirements, which may be unique from others. It is concerned and demands a system as faster, more accurate, cheaper and more extension computation. In digital image processing the image of object can be encountered and image processing is made and the missing image is detected.

Revised Manuscript Received on May 22, 2020.

* Correspondence Author

S. Bharathi*, Department of EEE, KPRIET College, Coimbatore, India.

K. Madhuleka, Department of EEE, KPRIET College, Coimbatore, India.

Prof. V. J. Vijayalakshmi, Department of EEE, KPRIET College, Coimbatore, India.

Dr. R. Uthirasamy, Department of EEE, KPRIET College, Coimbatore, India.

(c) The Authors. Published by Blue Eyes Intelligence Engineering and Sciences Publication (BEIESP). This is an open access article under the CC BY-NC-ND license (http://creativecommons.org/licenses/by-nc-nd/4.0/)

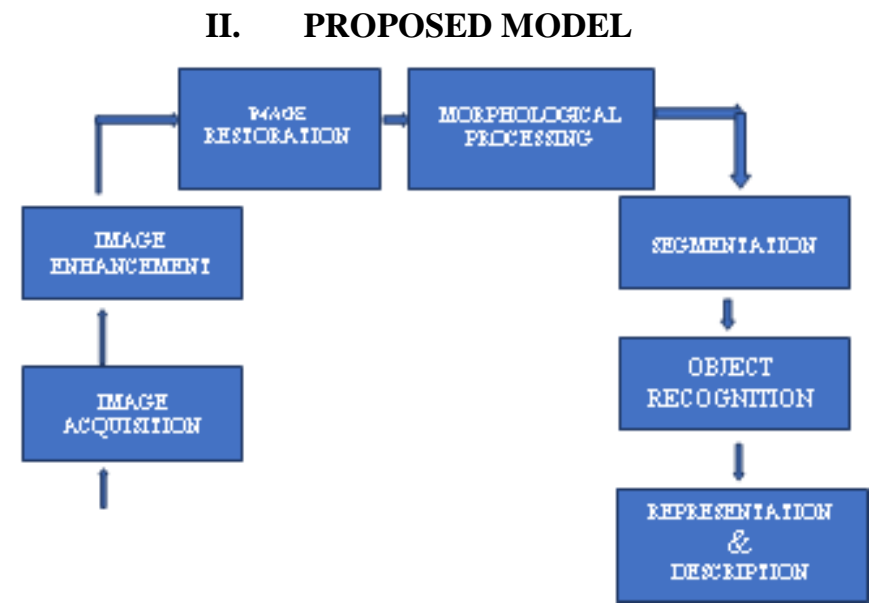

Fig. 1: Block Diagram of Digital Image Processing

In this block diagram, original image is acquisited it means the analog image is converted into digital image. Then the image enhanced for the further process. In image restoration the blur or noise image is restorted into new image. The pixel value of the image is determined by using the morphological process. Edge detection and the segmentation process are done to segment the required image. The last key stage of image processing is to recognized the required object in the image.

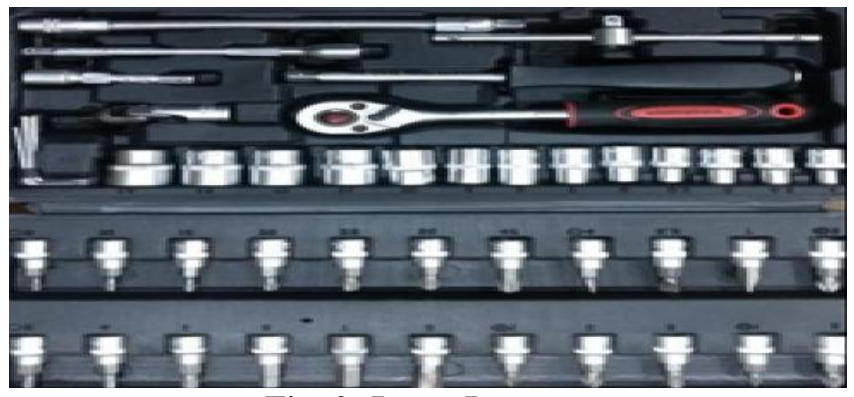

Fig. 2: Input Image

In Fig. 2 is the input image loaded as the input and it can be calling as Input data from database. To resize the image the image acquisition process is used.

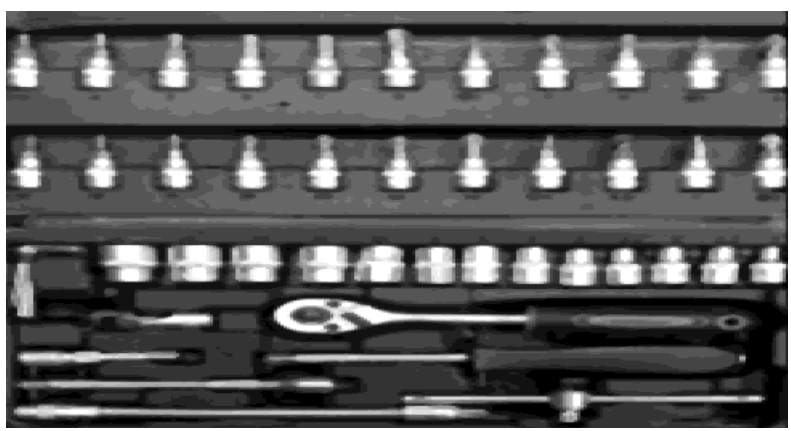

Fig. 3: Filtered Image

In the Fig. 3 image pre-processing and smoothing technique is used to filter and remove the noises.

Published By:

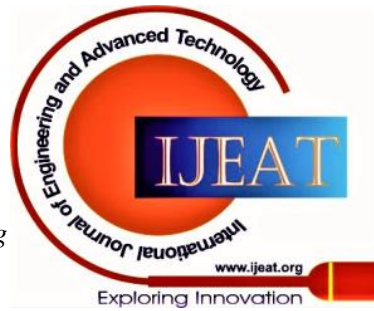


By adjusting the image intensity the enhance contrast is used.

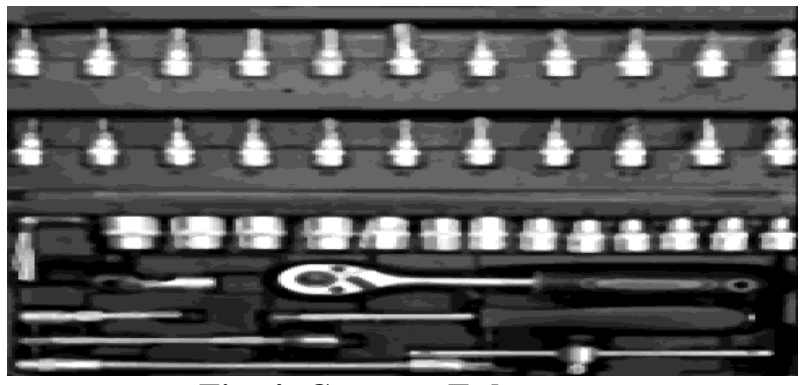

Fig. 4: Contrast Enhance

By adjusting the image intensity the enhance contrast is used in the Fig. 4.

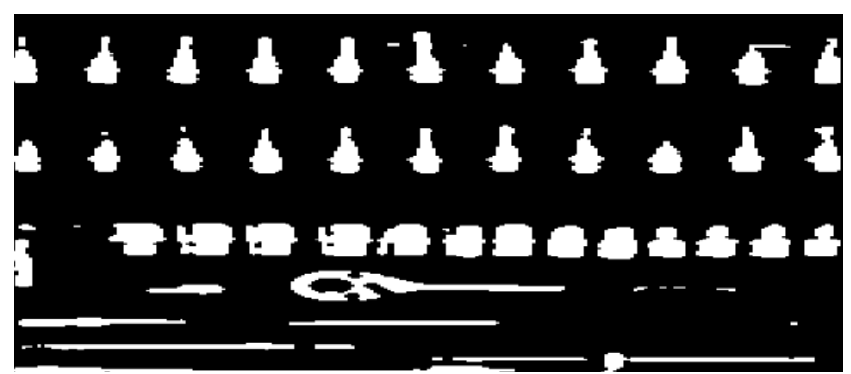

Fig. 5: RGB to BW 3

In the Fig.5 RGB to BW conversion is used to convert matrix to grayscale image.

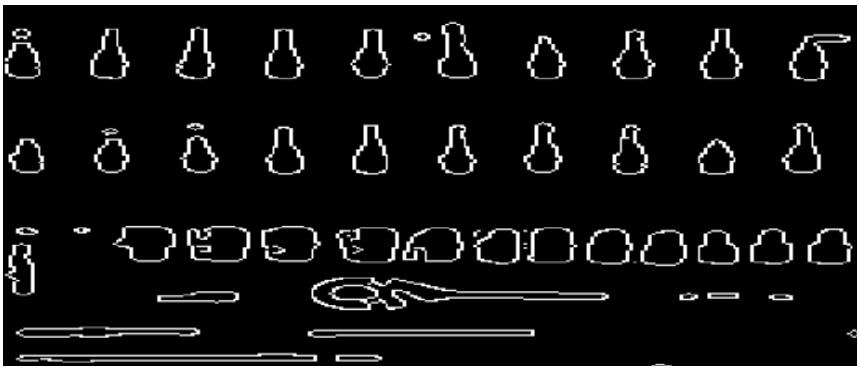

Fig. 6: Canny Edge Detection 3

To detect the edges of the image canny edge detection is used in the Fig. 6.
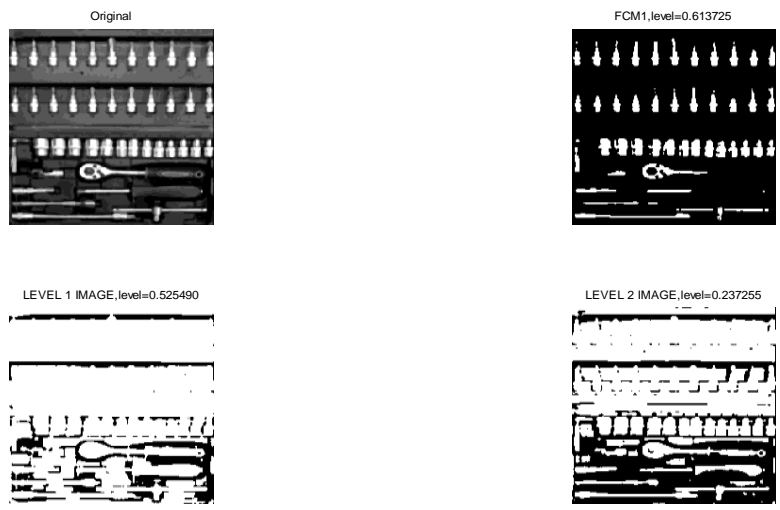

Fig. 7: Segmentation and Morphological Operations

In the Fig. 7 and 8 the segmentation and morphological operations are carried out for image thresholding using Otsu's method. For this process first convert image into binary image based on threshold. The thresholding is carried out by 3-class fuzzy means clustering

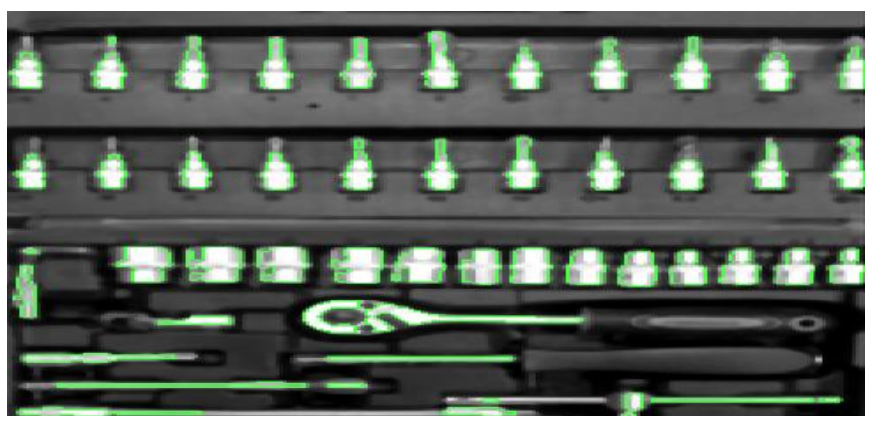

Fig. 8: Segmented Image Identification

\section{RESULTS}

In this paper we have done image acquisition, image enhancement and in this project we have count the number of objects in the image obtained by converting it into a grey scale image. And the results are obtained by using the applications.

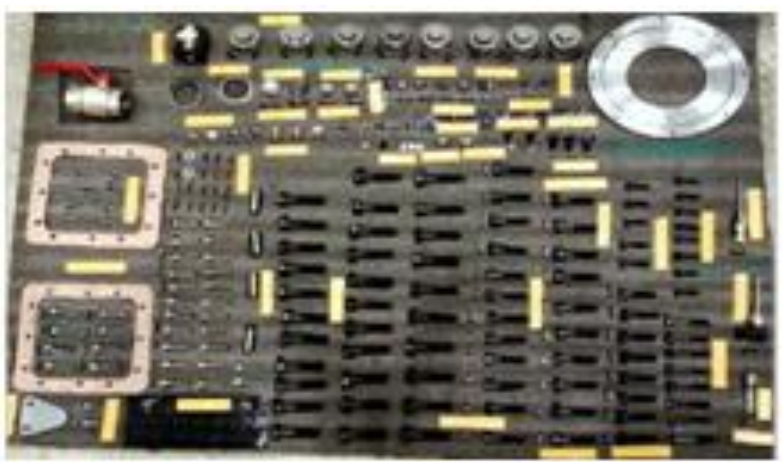

Fig. 9: Original Image

The original image is shown in Fig. 9. The original image is enhanced as shown in Fig.10 to remove the noise content and to improve the sharpness of the image.

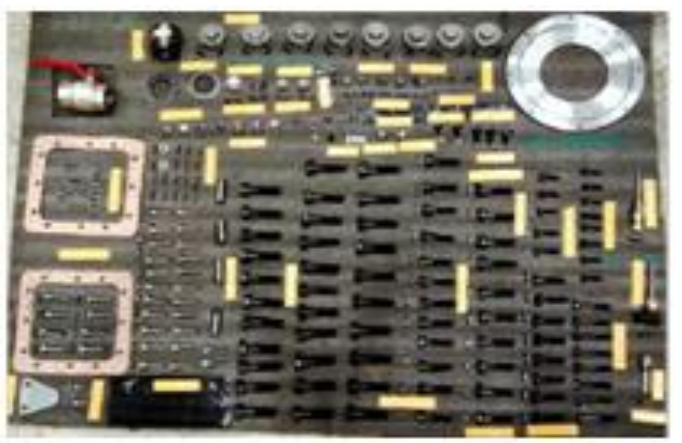

Fig. 10: Image Enhancement - contrast adjustment

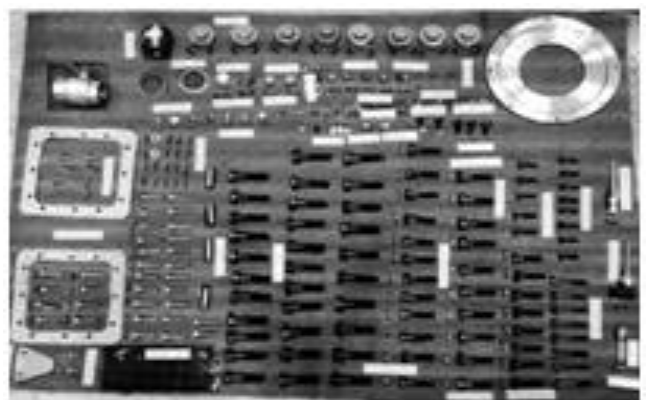

Fig. 11: Image Enhancement- rgb to gray scale

Published By:

Blue Eyes Intelligence Engineering

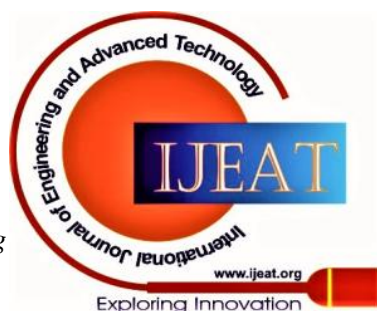




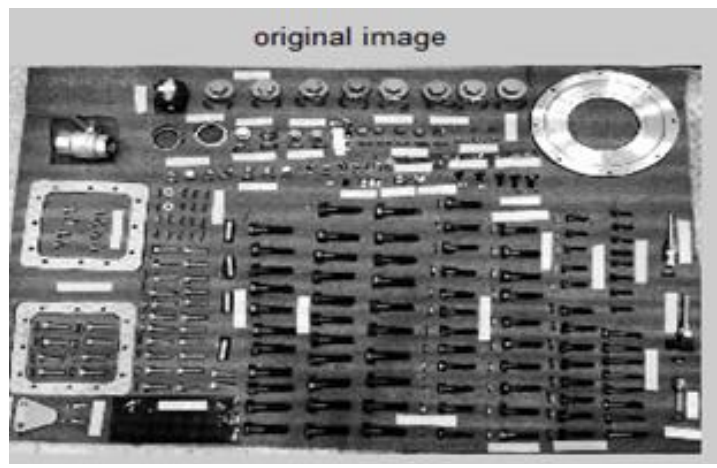

Fig. 12: Original image before edge detection

The image shown in Fig.11 and Fig.12 represents the image enhancement and the image before edge detection. The components used in the manufacturing of wind turbines are considered as sample images and image processing is implemented to count the missing objects in the wind turbine. Fig.13 shows the image after edge detection process.

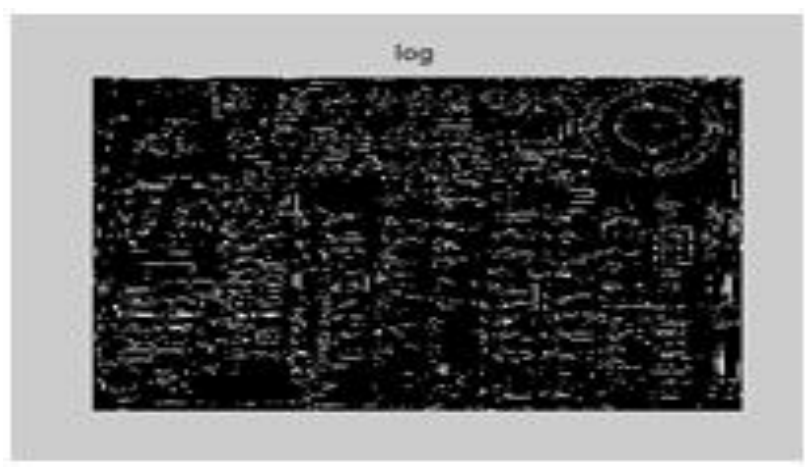

Fig. 13: Image after Edge Detection

\section{CONCLUSION}

This paper reveals the concept of detecting the missing components in the wind turbine using application. And also this project is put forward for the pattern identification technique using digital image processing to count the missing objects during the manufacturing of wind turbines. Though there are various techniques available to detect the missing objects, this method provides a better result and the complexity is reduced.

\section{REFERENCES}

1. Priya Tiwari, Dr. Naveen Dhillon and Er. Kuldeep Sharma. (2013) 'Analysis of Image Restoration Techniques for Developing Better Restoration Method' Vol.3, No.41.

2. Shilpa Rani, Sonika Jindal, Bhavneet Kaur (2016), Vol. 150 - No.12, September 2016. A Brief Review on Image Restoration Techniques. International Journal of computer Application.

3. Digital Signal Processing using Matlab by VinayK.Ingle\& John G.Proakis, 2007 ,Thomson Learning.

4. Fundamentals of Digital Signal Processing using Matlab by Robert J.Schilling\& Sandra L. Harris,2007, Thomson Learning.

5. Algorithms and Applications", Prentice Hall of India.

6. Fundamentals of Digital Image Processing by Anil Kumar Jain, 2001, PHI.

7. A.M.Raid1, W.M.Khedr2, M.A.El-dosuky1 and Mona Aoud1.Vol. 4, No.3, June 2014. Image restoration based on morphological operations. (IJCSEIT).

8. Mathrithakur, ShilpaChadury.Volume 14 Number 4 - Aug 2014.Image Restoration Based OnDeconvolution by Richardson Lucy Algorithm. International Journal of Engineering Trends and Technology (IJETT).
9. Y. Jia, E. Shelhamer, J. Donahue, S. Karayev, J. Long, R. Girshick, S Guadarrama, and T. Darrell, "Caffe: Convolutional architecture for fast feature embedding," in ACM MM, 2014.

\section{AUTHORS PROFILE}

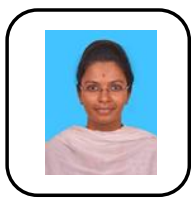

S. Bharathi final year student pursuing Bachelor degree in Electrical and Electronics Engineering at KPR Institute of Engineering and Technology, Coimbatore, India.

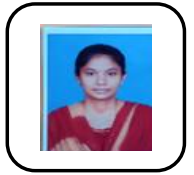

K. Madhuleka final year student pursuing Bachelor degree in Electrical and Electronics Engineering at KPR Institute of Engineering and Technology, Coimbatore, India.

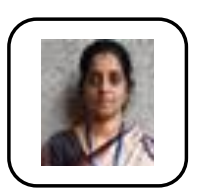

Ms. V. J. Viayalakshmi received her M.E degree from Anna University and B.E from Sri Ramakrishna Engineering College. She is having 9 years of teaching experience. She has published 18 papers in conferences and 24 papers in International journals.

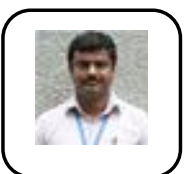

Dr. R. Uthirasamy received his Master of Engineering degree in Power Electronics and Drives from Government College of Engineering (GCE), Salem in 2007 and Ph.D. degree from Anna University, Chennai in 2016. He was a Gold Medalist in his UG Program. He has received Best Paper Award for his research articles.

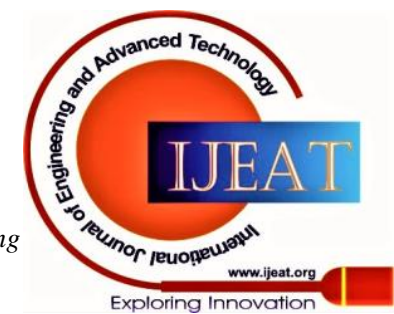

